Review

\title{
Symptomatic polyautoimmunity at diagnosis of 1463 childhood-onset lupus: A Brazilian multicenter study
}

\author{
Debora N. Setoue ${ }^{a}$, Ana C. Pitta ${ }^{a}$, Fernanda J. Fiorot ${ }^{\mathrm{a}}$, Mariana M. Nastri ${ }^{\mathrm{a}}$, Glaucia V. Novak ${ }^{\mathrm{a}}$, \\ Beatriz C. Molinari $^{\mathrm{a}}$, Juliana C. Oliveira ${ }^{\mathrm{a}}$, Natali W. Gormezano ${ }^{\mathrm{a}, \mathrm{b}}$, Ana P. Sakamoto ${ }^{\mathrm{c}}$, \\ Maria T. Terreri ${ }^{\mathrm{c}}$, Rosa M. Pereira ${ }^{\mathrm{b}}$, Claudia Saad-Magalhães ${ }^{\mathrm{d}}$, Adriana M. Sallum ${ }^{\mathrm{a}}$, Katia Kozu ${ }^{\mathrm{a}}$, \\ Melissa M. Fraga ${ }^{c}$, Daniela P. Piotto ${ }^{c}$, Gleice Clemente ${ }^{c}$, Roberto Marini ${ }^{e}$, Hugo R. Gomes ${ }^{f}$, \\ Carlos N. Rabelo-Junior ${ }^{g}$, Marta M. Felix ${ }^{\mathrm{h}}$, Maria C. Ribeiro ${ }^{\mathrm{i}}$, Rozana G. Almeida ${ }^{\mathrm{j}}$, Ana P. Assad ${ }^{\mathrm{b}}$, \\ Silvana B. Sacchetti ${ }^{\mathrm{k}}$, Leandra C. Barros ${ }^{1}$, Eloisa Bonfá ${ }^{\mathrm{b}}$, Clovis A. Silva ${ }^{\mathrm{a}, \mathrm{b}, *}$, Brazilian Childhood- \\ onset Systemic Lupus Erythematosus Group
}

\footnotetext{
a Pediatric Rheumatology Unit, Children's Institute, Hospital das Clinicas HCFMUSP, Faculdade de Medicina, Universidade de São Paulo, São Paulo, Brazil

${ }^{\mathrm{b}}$ Division of Rheumatology Hospital das Clinicas HCFMUSP, Faculdade de Medicina, Universidade de São Paulo, São Paulo, Brazil

${ }^{\mathrm{c}}$ Pediatric Rheumatology Unit, Universidade Federal de São Paulo, São Paulo, Brazil

d Pediatric Rheumatology Division, São Paulo State University (UNESP), Botucatu, Brazil

e Pediatric Rheumatology Unit, State University of Campinas (UNICAMP), Campinas, Brazil

${ }^{\mathrm{f}}$ Pediatric Rheumatology Unit, Ribeirão Preto Medical School, University of São Paulo, Ribeirão Preto, Brazil

${ }^{g}$ Pediatric Rheumatology Unit, Hospital Geral de Fortaleza, Fortaleza, Brazil

${ }^{\mathbf{h}}$ Pediatric Rheumatology Unit, Rio de Janeiro Federal University (IPPMG-UFRJ), Rio de Janeiro, Brazil

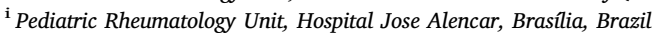

${ }^{\mathbf{j}}$ Pediatric Rheumatology Unit, Pedro Ernesto University Hospital, Rio de Janeiro, Brazil

k Pediatric Rheumatology Unit, Irmandade da Santa Casa de Misericórdia de São Paulo, São Paulo, Brazil

${ }^{1}$ Pediatric Rheumatology Unit, Federal University of Bahia, Brazil
}

\section{A R T I C L E I N F O}

\section{Keywords:}

Childhood-onset systemic lupus erythematosus Polyautoimmunity

Multiple autoimmune syndrome

SLICC

Disease activity

\begin{abstract}
A B S T R A C T
Objective: To evaluate symptomatic polyautoimmunity (PA) at childhood-onset systemic lupus erythematosus (cSLE) diagnosis, and its association with demographic data, disease activity, clinical manifestations and laboratorial abnormalities in a large Brazilian cSLE population.

Methods: A multicenter retrospective study was performed in 1463 cSLE(ACR criteria) patients from 27 Pediatric Rheumatology services. Symptomatic PA was defined according to the presence of more than one concomitant autoimmune disease(AD) and symptomatic multiple autoimmune syndrome(MAS) was defined as three or more AD. An investigator meeting was held to define the protocol. Demographic data, SLICC classification criteria and SLEDAI-2K were evaluated.

Results: At cSLE diagnosis symptomatic PA was observed in 144/1463(9.8\%) and symptomatic MAS occurred in solely $10 / 1463(0.7 \%)$. In the former group the more frequently observed associated AD were Hashimoto thyroiditis $n=42 / 144(29 \%)$, antiphospholipid syndrome $n=42 / 144(29 \%)$, autoimmune hepatitis $n=26$ / $144(18 \%)$ and type 1 diabetes mellitus $n=23 / 144(15.9 \%)$. Further comparisons between cSLE patients with and without PA showed a higher median age $(p=0.016)$ and lower mean SLICC criteria $(p=0.039)$ in those with PA. Additionally, these cSLE patients had less renal involvement(35\% vs. 44\%, $p=0.038$ ) and red blood cell cast( $6 \%$ vs. $12 \%, p=0.042)$ and more antiphospholipid antibodies(29\% vs. $15 \%, p<0.0001)$.

Conclusions: Approximately 10\% of cSLE had symptomatic PA at diagnosis, particularly endocrine autoimmune disorders and antiphospholipid syndrome. Lupus was characterized by a mild disease onset and MAS was infrequently evidenced. Further studies are necessary to determine if this subgroup of cSLE patients have a distinct genetic background with a less severe disease and a better long-term outcome.
\end{abstract}

\footnotetext{
* Corresponding author at: Av. Dr. Eneas Carvalho Aguiar, 647 - Cerqueira César, São Paulo 05403-000, SP, Brazil.

E-mail address: clovis.silva@hc.fm.usp.br (C.A. Silva).
} 


\section{Introduction}

Childhood-onset systemic lupus erythematosus (cSLE) is a chronic autoimmune illness with a broad clinical and laboratory spectrum, which may involve any organs and systems [1-6]. One hallmark of the cSLE is that autoantibodies are directed against several cellular antigens and with possibility of concomitant multiple organ-specific autoimmune diseases (AD) [1, 7, 8].

Polyautoimmunity (PA), which is defined according to the presence of more than one $\mathrm{AD}$ in each patient [9-11], has been described in up to $41 \%$ of adult SLE [9]. However, to our knowledge the prevalence of PA in cSLE in a large series has not been studied and the report of this very rare association is restricted to only a few case series [7, 12].

Therefore, the objective of this multicenter cohort study was to evaluate symptomatic PA at cSLE diagnosis and the possible association with demographic data, disease activity, clinical manifestations and laboratorial abnormalities in a large Brazilian cSLE population.

\section{Methods}

\subsection{Study design and patients}

This is a retrospective multicenter observational cohort study including 1697 consecutive patients followed in 27 Pediatric Rheumatology tertiary referral services in Brazil. Two hundred thirtyfour cSLE patients were excluded due to: incomplete medical charts $(n=135)$ and undifferentiated connective tissue disorder with 3 or fewer American College of Rheumatology (ACR) criteria $(n=99)$. The remaining 1463 cSLE patients comprised the study group and all of them fulfilled the ACR criteria [13], with disease onset before 18 years of age [5]. All Ethics Committees of all participating centers in Brazil approved this study, after the approval of the coordinating center.

An investigator meeting was held for this study in Brasilia, at the Brazilian Congress of Rheumatology in 2016, to refine a previous protocol including definitions of clinical and disease activity parameters. One investigator with Brazilian Board Pediatric Rheumatology Certifying Examination supervised data collection in each center. Discrepancies were sorted out by one or more rounds of queries for accuracy. Data was collected between September 2016 and May 2017.

Patient's medical charts were carefully reviewed according to an extensive standardized protocol for demographic data, clinical features and laboratory findings at cSLE diagnosis.

\subsection{Demographic data, clinical and laboratory assessment, and disease activity at cSLE diagnosis}

Demographic data included age at cSLE diagnosis and gender. Ethnics groups were classified in: Caucasian (patients with white European ancestors), Afro-Latin Americans (patients with at least one African ancestor), Asian (patients with at least one Asian ancestor) and other/unknown [6]. Definitions of clinical and immunologic criteria were used according to Systemic Lupus International Collaborating Clinics Classification Criteria for Systemic Lupus Erythematosus (SLICC) [14]. SLE Disease Activity Index 2000 (SLEDAI-2K) was used to assess disease activity [15].

Laboratory assessment included retrospective analysis of complete blood cell count, urinalysis and 24-h urine protein excretion or urine protein/creatinine ratio. Complement levels (CH50, C3 and C4) were assessed by immunodiffusion, turbidimetric immunoassay or immunonephelometry. Antinuclear antibodies (ANA) were tested by indirect immunofluorescence. Anti-double-stranded DNA (anti-dsDNA) were evaluated by indirect immunofluorescence or Enzyme Linked Immuno Sorbent Assay (ELISA); anti-Sm by passive hemagglutination or ELISA; anticardiolipin IgG and IgM by ELISA; and anti- $\beta$ glycoprotein I IgG and IgM autoantibodies by ELISA. All of them were carried out at each center. The cut-off values from the kit manufacturer were used to define abnormal values. Lupus anticoagulant was detected according to the guidelines of the International Society on Thrombosis and Hemostasis [16].

\subsection{Polyautoimmunity diagnosis}

Symptomatic PA was defined according to the presence of more than one $\mathrm{AD}$ in each patient. Symptomatic multiple autoimmune syndrome (MAS) was defined as three or more AD [9]. The following symptomatic $\mathrm{AD}$ were carefully assessed in all patient's chart: antiphospholipid syndrome [17, 18], autoimmune gastritis [19], autoimmune hepatitis [20-23], autoimmune sclerosing cholangitis [23, 24], autoimmune vitiligo [25], celiac disease [26], Hashimoto thyroiditis [27], Sjögren syndrome [28], type 1 diabetes mellitus (T1DM) [29] and myasthenia gravis [30].

Antiphospholipid syndrome was diagnosed according to the preliminary criteria for the classification of pediatric antiphospholipid syndrome [17, 18]. Autoimmune gastritis was defined by clinical manifestations (megaloblastic anemia secondary to vitamin B12 and iron deficiency, and diarrhea) associated with gastric atrophy confirmed by histology, positive parietal cell autoantibody and anti-intrinsic factor positivity [19]. Autoimmune hepatitis was defined as a progressive chronic hepatitis of unknown origin, with elevated transaminase levels, hypergammaglobulinemia, serum autoantibodies and histological characteristics [20-23]. Autoimmune sclerosing cholangitis was diagnosed according to clinical/biochemical features of cholestasis, presence of antimitochondrial antibody, and histological or cholangiographic findings [23, 24]. Autoimmune vitiligo was characterized by destruction of skin melano-cytes, hypopigmented and asymptomatic macules with demarcated margins and association with AD [25].

Celiac disease was defined by at least four of the following: clinical manifestations (such as chronic diarrhea, stunting and/or iron deficiency anemia), positivity for immunoglobulin A class anti-endomysial antibody, HLA-DQ2 or DQ8 genotype, small intestine biopsy compatible with celiac enteropathy, and response to gluten-free diet [26].

Hashimoto's thyroiditis was defined as clinical manifestations (such as goiter, increasingly fatigue, sluggish, dry skin, constipation, and/or hoarse voice) associated with reduced free thyroxine (T4) and elevated TSH levels [27]. The presence of at least one antithyroid antibody [antithyroid peroxidase antibody, anti-thyroglobulin antibody or antithyroid stimulating hormone receptor antibody] was required to characterize Hashimoto's thyroiditis [7].

Sjögren's syndrome was established according to the AmericanEuropean Consensus Group [28]. T1DM was diagnosed by polyuria, polydipsia and unexplained weight loss, and increased plasma glucose $\geq 200 \mathrm{mg} / \mathrm{dL}$ at any time of day or fasting glucose $\geq 126 \mathrm{mg} / \mathrm{dL}$ [29], and without glucocorticosteroid use. Myastenia gravis was diagnosed according to ACR nomenclature and case definitions for neuropsychiatric lupus syndromes [30].

\subsubsection{Statistical analysis}

The results for the continuous variables were presented by median (minimum and maximum value) or mean \pm standard deviation (SD), and for categorical variables presented as frequency (percentage). The scores that had normal and abnormal distributions were compared by Student's $t$-test and Mann-Whitney test, respectively. The differences of categorical variables were calculated by Fisher's exact test or Pearson chi-square test, as appropriated. The adopted significance levels in all analyses were set at $5 \%$.

\section{Results}

Symptomatic PA was observed in 144/1463 (9.8\%) at cSLE diagnosis. The following symptomatic $\mathrm{AD}$ were observed in cSLE patients at diagnosis: Hashimoto thyroiditis $n=42 / 144$ (29\%), antiphospholipid syndrome $n=42 / 144$ (29\%), autoimmune hepatitis $n=26 / 144$ 
Table 1

Demographic data and disease activity score in 1463 childhood-onset systemic lupus erythematosus (cSLE) patients according to the presence of symptomatic polyautoimmunity (PA) at diagnosis.

\begin{tabular}{llll}
\hline Variables & $\begin{array}{l}\text { With PA } \\
(n=144)\end{array}$ & $\begin{array}{l}\text { Without PA } \\
(n=1319)\end{array}$ & $p$ \\
\hline $\begin{array}{l}\text { Demographic data } \\
\text { Age at cSLE diagnosis, years, } \\
\quad 1463\end{array}$ & $13(0.3-18)$ & $12(0.4-18)$ & 0.016 \\
$\quad$ Male gender, $n=222$ & $19(13)$ & $203(15)$ & 0.486 \\
$\quad$ Ethnic groups, $n=1448$ & $65(46)$ & $671(51)$ & 0.461 \\
$\quad \begin{array}{ll}\text { Caucasian } \\
\text { Afro-Latin American }\end{array}$ & $61(44)$ & $432(33)$ & - \\
$\quad \begin{array}{l}\text { Asian } \\
\quad \text { Other/unknown }\end{array}$ & $1(0.7)$ & $6(0.5)$ & - \\
$\begin{array}{l}\text { Disease activity score at diagnosis, } \\
\quad \text { SLEDAI-2 K, } n=1400\end{array}$ & $13(1-48)$ & $199(15)$ & - \\
$\quad$ SLEDAI-2 K $\geq 8, n=1400$ & $111(80)$ & $1079(85)$ & 0.139 \\
\end{tabular}

Results are presented in $n$ (\%) and median (range), SLEDAI-2K - Systemic Lupus Erythematosus Disease Activity Index 2000.

(18\%), T1DM $n=23 / 144$ (15.9\%), autoimmune vitiligo $n=4 / 144$ (2.8\%), celiac disease $n=3 / 144$ (2\%), Sjögren syndrome $n=1 / 144$ $(0.7 \%)$, autoimmune gastritis $n=1 / 144(0.7 \%)$, primary sclerosing cholangitis $n=1 / 144(0.7 \%)$ and myasthenia gravis $n=1 / 144(0.7 \%)$.

Symptomatic MAS was observed in 10/1463 (0.7\%) patients, particularly T1DM and autoimmune hepatitis diseases in $6 / 10$ patients.

Table 1 shows demographic data and disease activity score in 1463 cSLE patients according to the presence of symptomatic PA at diagnosis. The median age at cSLE diagnosis was higher in cSLE patients with PA compared to those without this condition [13 (0.3-18) vs. 12 (0.4-18) years, $p=0.016]$. No differences were evidenced between gender, ethnicity and SLEDAI- $2 \mathrm{~K}$ score between the two groups $(p>0.05$, Table 1).

Table 2 illustrates clinical and immunological definitions of SLICC in 1463 cSLE patients according to the presence of symptomatic PA at diagnosis. The median of SLICC criteria was lower in cSLE patients with PA compared to those without [6 (4-11) vs. 6 (4-13), $p=0.039$ ]. Frequencies of renal involvement ( $35 \%$ vs. $44 \%, p=0.038)$ and red blood cell cast ( $6 \%$ vs. $12 \%, p=0.042$ ) were reduced in the former group, whereas antiphospholipid antibodies were higher in cSLE with PA ( $29 \%$ vs. $15 \%, p<0.0001)$. No differences were evidenced in the other clinical manifestations and laboratorial tests in the two groups $(p<0.05$, Table 2).

\section{Discussion}

Our large Brazilian multicenter study demonstrated that almost $10 \%$ of cSLE had symptomatic PA at diagnosis, particularly endocrine autoimmune disorders and antiphospholipid syndrome. Patients with PA were older and had mild disease onset, and MAS was rarely observed.

The advantage of the study was the large sample size of the cSLE population followed at 27 Brazilian University Services, including centers of all regions of our country. Other relevant point was the use of a standardized database to minimize bias. The main weakness observed herein was the retrospective design, inclusion of only symptomatic PA which may have underestimated subclinical PA, and the lack of familiar history of autoimmunity.

The cSLE pathophysiology consists of an exacerbated response of B cells and T cells, loss of tolerance to autoantigens and the possibility of multiple organ-specific autoantibodies and PA [7, 31, 32]. The concomitance of one or several AD in cSLE patients observed herein corroborates with the hypothesis that these diseases may share the same underlying mechanism [9]. In fact, a lower frequency of nephritis was observed in this subgroup of patients suggesting a distinct phenotype
Table 2

Clinical and immunological definitions of Systemic Lupus International Collaborating Clinics Classification Criteria (SLICC) in 1463 childhood-onset systemic lupus erythematosus (cSLE) patients according to the presence of symptomatic polyautoimmunity (PA) at diagnosis.

\begin{tabular}{|c|c|c|c|}
\hline Variables & $\begin{array}{l}\text { With PA } \\
(n=144)\end{array}$ & $\begin{array}{l}\text { Without PA } \\
(n=1319)\end{array}$ & $p$ \\
\hline $\begin{array}{l}\text { Number of SLICC criteria (0-17), } \\
\qquad n=1463\end{array}$ & $6(4-11)$ & $6(4-13)$ & 0.039 \\
\hline 1. Acute cutaneous lupus & $92(64)$ & $849(64)$ & 0.909 \\
\hline Malar rash & 79 (55) & $699(53)$ & 0.670 \\
\hline Bullous lupus & $4(3)$ & $22(2)$ & 0.315 \\
\hline Toxic epidermal necrolysis & $1(0.7)$ & $1(0.1)$ & 1.000 \\
\hline Maculopapular lupus rash & $8(6)$ & $65(5)$ & 0.743 \\
\hline Photosensitive lupus rash & $64(44)$ & $605(46)$ & 0.745 \\
\hline Subacute cutaneous lupus & $3(2)$ & $30(2)$ & 1.000 \\
\hline 2. Chronic cutaneous lupus & $7(5)$ & $84(6)$ & 0.477 \\
\hline Discoid rash & $6(4)$ & $69(5)$ & 0.582 \\
\hline $\begin{array}{l}\text { Hypertrophic (verrucous) } \\
\text { lupus }\end{array}$ & $1(0.7)$ & $1(0.1)$ & 1.000 \\
\hline Lupus panniculitis & $0(0)$ & $7(0.5)$ & 1.000 \\
\hline Mucosal lupus & $0(0)$ & $1(0.1)$ & 1.000 \\
\hline Lupus erythematosus tumidus & $0(0)$ & $2(0.2)$ & 1.000 \\
\hline Chillblains lupus & $0(0)$ & $1(0.1)$ & 1.000 \\
\hline Overlap & $0(0)$ & $5(0.4)$ & 1.000 \\
\hline 3. Oral ulcers & $50(35)$ & $453(34)$ & 0.928 \\
\hline Palate & 22 (15) & 170 (13) & 0.422 \\
\hline Buccal & $35(24)$ & $329(25)$ & 0.867 \\
\hline Tongue & $5(3)$ & $25(2)$ & 0.209 \\
\hline Nasal & $1(0,7)$ & $16(1)$ & 1.000 \\
\hline 4. Nonscarring alopecia & $38(26)$ & $276(21)$ & 0.129 \\
\hline 5. Synovitis & $104(72)$ & $920(70)$ & 0.539 \\
\hline 6. Serositis & $37(26)$ & $383(29)$ & 0.400 \\
\hline Pleuritis & $22(15)$ & 238 (18) & 0.410 \\
\hline Pericarditis & 25 (17) & $258(20)$ & 0.526 \\
\hline 7. Renal & $50(35)$ & $577(44)$ & 0.038 \\
\hline Proteinuria $>0.5 \mathrm{~g} /$ day & $49(34)$ & $526(40)$ & 0,172 \\
\hline Red blood cells casts & $9(6)$ & $157(12)$ & 0.042 \\
\hline 8. Neurologic & $17(12)$ & $151(11)$ & 0.898 \\
\hline 9. Hemolytic anemia & $36(25)$ & $281(21)$ & 0.307 \\
\hline 10.Leukopenia or lymphopenia & $66(46)$ & $555(42)$ & 0.387 \\
\hline 11.Thrombocytopenia & $26(18)$ & 248 (19) & 0.827 \\
\hline \multicolumn{4}{|l|}{ Immunological criteria } \\
\hline 12. Antinuclear antibody & $140(97)$ & $1240(94)$ & 0.114 \\
\hline 13. Anti-dsDNA antibody & $94(65)$ & $807(61)$ & 0.337 \\
\hline 14. Anti-Sm antibody & $38(26)$ & $306(23)$ & 0.391 \\
\hline 15. Antiphospholipid antibody & $42(29)$ & 201 (15) & $<0.0001$ \\
\hline $\begin{array}{l}\text { 16. Low complement (C3, C4 or } \\
\text { CH50) }\end{array}$ & $68(47)$ & $615(47)$ & 0.892 \\
\hline 17. Isolated direct Coombs test & $9(6)$ & $83(6)$ & 0.984 \\
\hline
\end{tabular}

Results are presented in $n(\%)$ and median (range).

with milder cSLE, contrasting with almost $50 \%$ nephritis in overall cSLE at disease onset $[6,33]$.

We further confirmed and extended previous observation of approximately $2-3 \%$ associated antiphospholipid syndrome at cSLE presentation $[6,33]$. We further demonstrated that this frequency was comparable to symptomatic autoimmune thyroid disease, particularly Hashimoto's thryroiditis that was reported during follow-up in 5\% of cSLE [7] and was not described at disease onset in a French study [33].

The occurrence of association of lupus and autoimmune hepatitis was reported from $1 \%$ to $10 \%$ of cSLE and adult SLE populations during follow-up [23, 34] and $0.4 \%$ at disease diagnosis [20], a frequency comparable to the one observed herein (1.7\%). T1DM was also an uncommon autoimmune endocrine disorder (1.4\%) and not related to glucocorticosteroid therapy [35].

MAS in adults had a distinct overlap profile compared to children with SLE. In adults the most frequent associated autoimmune disorders with SLE were Sjögren syndrome and rheumatoid arthritis [9], whereas in children and adolescents we observed more often T1DM and autoimmune hepatitis diseases.

In conclusion, $10 \%$ of cSLE had symptomatic PA at diagnosis with 
mild disease onset and particularly associated with endocrine autoimmune disorders and antiphospholipid syndrome. Further studies are necessary to determine if this subgroup of cSLE patients have a distinct genetic background with a less severe disease and a better long-term outcome.

\section{Disclosure statement}

The authors have declared no conflicts of interest.

\section{Funding}

This study was supported by grants from Fundação de Amparo à Pesquisa do Estado de São Paulo (FAPESP 2015/03756-4 to EB and CAS), Conselho Nacional de Desenvolvimento Científico e Tecnológico (CNPq 303752/2015/7 to MTT, 301805/2013-0 to RMRP, 305068/ 2014-8 to EB and $303422 / 2015-7$ to CAS), Federico Foundation (to RMRP, EB and CAS) and by Núcleo de Apoio à Pesquisa "Saúde da Criança e do Adolescente" da USP (NAP-CriAd) to CAS.

\section{Acknowledgements}

Our gratitude to Clara Malagón and we also thank Ulysses DoriaFilho for carried out the statistical analysis. The authors thank the following Pediatric Rheumatology Divisions and colleagues for including their patients: Pediatric Rheumatology Unit, FMUSP (Lucia Maria Arruda Campos); Pediatric Rheumatology Unit, UNIFESP (Octavio Peracchi, Claudio Arnaldo Len); Division of Rheumatology, FMUSP (Nadia Emi Aykawa); UNESP (Luciana Gomes Portásio, Barbara Geane Fonseca), Irmandade da Santa Casa de Misericórdia de São Paulo (Maria Carolina Santos, Eunice Okuda); State University of Campinas (Simone Appenzeller); Ribeirão Preto Medical School - University of São Paulo (Virginia Paes Leme Ferriani); Hospital Infantil Darcy Vargas (Cassia Passarelli); Hospital Municipal Infantil Menino Jesus (Simone Lotufo, Tânia Caroline Monteiro de Castro); Pontifical Catholic University of Sorocaba (Valéria C. Ramos); Hospital Geral de Fortaleza, Fortaleza (Marco Felipe Castro Silva, Ana Raquel Feitosa); Instituto de Puericultura e Pediatria Martagão Gesteira/Universidade Federal do Rio de Janeiro (Sheila Feitosa Oliveira, Marta M Felix); Hospital Jose Alencar, Brasília (Maria Custódia Machado Ribeiro); Hospital Universitário Pedro Ernesto, Rio de Janeiro (Flávio Roberto Sztajnbok); Hospital Evangélico de Curitiba (Paulo F. Spelling), Hospital Albert Sabin (Luciana Brandão Paim), Rheumatology Division, Federal University of Rio de Janeiro (Blanca Bica), Lauro Vanderley University Hospital, João Pessoa (Evaldo G. Sena); Federal University of Pará (Ana Julia Pantoja Moraes); Obras Sociais Irmã Dulce, Salvador (Ana M. Rolim); Hospital Evangélico de Curitiba, Curitiba (Paulo F. Spelling); Hospital Criança Conceição, Porto Alegre (Iloite M. Scheibel); Federal University of Pernambuco (André S. Cavalcanti); Federal University of Mato Grosso do Sul (Erica N. Matos); Federal University of Bahia (Teresa C. Robazzi); University of Brasilia (Luciano J. Guimarães); Federal University of Minas Gerais (Flávia P. Santos); Hospital Municipal Piedade, Rio de Janeiro (Cynthia T. Silva).

\section{References}

[1] Novak GV, Marques M, Balbi V, Gormezano NW, Kozu K, Sakamoto AP, et al. AntiRo/SSA and anti-La/SSB antibodies: association with mild lupus manifestations in 645 childhood-onset systemic lupus erythematosus. Autoimmun Rev 2017; 16:132-5.

[2] Silva CA. Childhood-onset systemic lupus erythematosus: early disease manifestations that the paediatrician must know. Expert Rev Clin Immunol 2016;12:907-10.

[3] Silva CA, Aikawa NE, Pereira RM, Campos LM. Management considerations for childhood-onset systemic lupus erythematosus patients and implications on therapy. Expert Rev Clin Immunol 2016;12:301-3.

[4] Klumb EM, Silva CA, Lanna CC, Sato EI, Borba EF, Brenol JC, et al. Consensus of the Brazilian Society of Rheumatology for the diagnosis, management and treatment of lupus nephritis. Rev Bras Reumatol 2015;55:1-21.
[5] Silva CA, Avcin T, Brunner HI. Taxonomy for systemic lupus erythematosus with onset before adulthood. Arthritis Care Res (Hoboken) 2012;64:1787-93.

[6] Gomes RC, Silva MF, Kozu K, Bonfá E, Pereira RM, Terreri MT, et al. Features of 847 childhood-onset systemic lupus erythematosus patients in three age groups at diagnosis: a Brazilian multicenter study. Arthritis Care Res (Hoboken) 2016;68:1736-41.

[7] Aikawa NE, Jesus AA, Liphaus BL, Silva CA, Carneiro-Sampaio M, Viana VS, et al. Organ-specific autoantibodies and autoimmune diseases in juvenile systemic lupus erythematosusand juvenile dermatomyositis patients. Clin Exp Rheumatol 2012;30:126-31.

[8] Valões CC, Molinari BC, Pitta AC, Gormezano NW, Farhat SC, Kozu K, et al. Antiribosomal P antibody: a multicenter study in childhood-onset systemic lupus erythematosus patients. Lupus 2017;26:484-9.

[9] Anaya JM. The diagnosis and clinical significance of polyautoimmunity. Autoimmun Rev 2014;13:423-6.

[10] Anaya JM, Rojas-Villarraga A, Mantilla RD, Arcos-Burgos M, Sarmiento-Monroy JC Polyautoimmunity in Sjögren syndrome. Rheum Dis Clin North Am 2016;42:457-72.

[11] Rojas-Villarraga A, Amaya-Amaya J, Rodriguez-Rodriguez A, Mantilla RD, Anaya JM. Introducing polyautoimmunity: secondary autoimmune diseases no longer exist. Autoimmune Dis 2012;2012:254319.

[12] Castiblanco J, Sarmiento-Monroy JC, Mantilla RD, Rojas-Villarraga A, Anaya JM. Familial aggregation and segregation analysis in families presenting autoimmunity, Polyautoimmunity, and multiple autoimmune syndrome. J Immunol Res 2015;2015:572353.

[13] Hochberg MC. Updating the American College of Rheumatology revised criteria for the classification of systemic lupus erythematosus. Arthritis Rheum 1997:40:1725.

[14] Petri M, Orbai AM, Alarcón GS, Gordon C, Merrill JT, Fortin PR, et al. Derivation and validation of the Systemic Lupus International Collaborating Clinics classification criteria for systemic lupus erythematosus. Arthritis Rheum 2012;64:2677-86.

[15] Gladman DD, Ibañez D, Urowitz MB. Systemic lupus erythematosus disease activity index 2000. J Rheumatol 2002;29:288-91.

[16] Brandt JT, Triplett DA, Alving B, Scharrer I. Criteria for the diagnosis of lupus anticoagulants: an update. On behalf of the subcommittee on lupus anticoagulant/ antiphospholipid antibody of the scientific and standardisation committee of the ISTH. Thromb Haemost 1995;74:1185-90.

[17] Avcin T, Cimaz R, Silverman ED, Cervera R, Gattorno M, Garay S, et al. Pediatric antiphospholipid syndrome: clinical and immunologic features of 121 patients in an international registry. Pediatrics 2008;122:e1100-7.

[18] Avcin T, Cimaz R, Rozman B. Ped-APS registry collaborative group. The Ped-APS registry: the antiphospholipid syndrome in childhood. Lupus 2009;18:894-9.

[19] De Block CE, De Leeuw IH, Van Gaal LF. Autoimmune gastritis in type 1 diabetes: a clinically oriented review. J Clin Endocrinol Metab 2008;93:363-71.

[20] Manns MP, Czaja AJ, Gorham JD, Krawitt EL, Vergani GM, Vergani D, et al Diagnosis and management of autoimmune hepatitis. Hepatology 2010;51:2193-213.

[21] Quaio CR, Carvalho JF, da Silva CA, Bueno C, Brasil AS, Pereira AC, et al. Autoimmune disease and multiple autoantibodies in 42 patients with RASopathies. Am J Med Genet A 2012;158A:1077-82.

[22] Deen ME, Porta G, Fiorot FJ, Campos LM, Sallum AM, Silva CA. Autoimmune hepatitis and juvenile systemic lupus erythematosus. Lupus 2009;18:747-51.

[23] Bozzini AB, Neder L, Silva CA, Porta G. Decreased health-related quality of life in children and adolescents with autoimmune hepatitis. J Pediatr (Rio J) 2018. http:// dx.doi.org/10.1016/j.jped.2017.10.013.

[24] Malik N, Venkatesh SK. Imaging of autoimmune hepatitis and overlap syndromes. Abdom Radiol 2017;42:19-27.

[25] Iannella G, Greco A, Didona D, Didona B, Granata G, Manno A, et al. Vitiligo: pathogenesis, clinical variants and treatment approaches. Autoimmun Rev 2016;15:335-43.

[26] Catassi C, Fasano A. Celiac disease diagnosis: simple rules are better than complicated algorithms. Am J Med 2010;123:691-3.

[27] Franklyn JA. Hypothyroidism. Medicine 2005;33:27-9.

[28] Vitali C, Bombardieri S, Jonsson R, Moutsopoulos HM, Alexander EL, Carsons SE, et al. Classification criteria for Sjögren's syndrome: a revised version of the European criteria proposed by the American-European Consensus Group. Ann Rheum Dis 2002;61:554-8.

[29] American Diabetes Association. Standards of medical care in diabetes 2007 (positional statement). Diabetes Care 2007;30:S4-41.

[30] American College of Rheumatology Ad Hoc committee on neuropsychiatric Lupus Syndromes. The American College of Rheumatology nomenclature and case definitions for neuropsychiatric lupus syndromes. Arthritis Rheum 1999;42:599-608.

[31] Franco JS, Amaya-Amaya J, Molano-González N, Caro-Moreno J, RodríguezJiménez M, Acosta-Ampudia Y, et al. Autoimmune thyroid disease in Colombian patients with systemic lupus erythematosus. Clin Endocrinol (Oxf) 2015;83:943-50.

[32] Campos LM, Kiss MH, D'Amico EA, Silva CA. Antiphospholipid antibodies and antiphospholipid syndrome in 57 children and adolescents with systemic lupus erythematosus. Lupus 2003;12:820-6.

[33] Bader-Meunier B, Armengaud JB, Haddad E, Salomon R, Deschênes G, Koné-Paut I, et al. Initial presentation of childhood-onset systemic lupus erythematosus: a French multicenter study. J Pediatr 2005;146:648-53.

[34] Irving KS, Sen D, Tahir H, Pilkington C, Isenberg DA. A comparison of autoimmune liver disease in juvenile and adult populations with systemic lupus erythematosus-a retrospective review of cases. Rheumatology 2007;46:1171-3.

[35] Kota SK, Meher LK, Jammula S, Kota SK, Modi KD. Clinical profile of coexisting conditions in type 1 diabetes mellitus patients. Diabetes Metab Syndr 2012;6:70-6. 